\title{
THE GLOBAL TRANSMISSION OF VOLATILITY IN THE FOREIGN EXCHANGE MARKET
}

\author{
Michael Melvin and Bettina Peiers Melvin*
}

\begin{abstract}
Volatility spillovers of the $\mathrm{DM} / \$$ and $¥ / \$$ exchange rate across regional markets are examined using the integrated volatility of highfrequency data. An analysis of quoting patterns reveals five distinct regions: Asia, Asia-Europe overlap, Europe, Europe-America overlap, and America. After reviewing theoretical foundations for persistence of volatility in dealership markets, regional volatility models are constructed where volatility in one region is a function of yesterday's volatility in that region ("heat-wave effect") and volatility in other regions ("meteorshower effect"). Evidence of statistically significant effects is found for both own-region and interregional spillovers, but the economic significance of own-region spillovers indicates that heat waves are more important than meteor showers.
\end{abstract}

\section{Introduction}

$\mathrm{I}$ $\mathrm{T}$ is a well-known stylized fact that foreign exchange (FX) rate dynamics are characterized by clusters of volatility. In seminal papers on the subject, Engle, Ito, and Lin (1990) and Ito, Engle, and Lin (1992) demonstrated the presence of meteor showers, or interregional volatility persistence, for the mid-1980s yen-dollar market. Further evidence on region-specific volatility clustering, or heat waves, was provided by Baillie and Bollerslev (1990) and Hogan and Melvin (1994).

However, these early studies faced extensive data limitations. In Engle et al. (1990), a daily opening and closing price for Tokyo and New York formed the basis for inferring volatility transmission. These opening and closing quotes were limited to one morning and one afternoon observation and hence did not reflect the actual level of activity occurring in the major foreign exchange trading centers, notably Europe.

More recently, high-frequency data sets have allowed the issue to be reconsidered in a continuous-time setting. Dacorogna et al. (1993) and Andersen and Bollerslev (1997) demonstrate that intradaily seasonality in FX volatility contains a geographic component reflecting the timing of business activity in the major geographical trading zones.

Based on this finding, this paper will examine volatility persistence in a framework where clusters of highfrequency quote activity will define the opening and closing times of trading centers. Specifically, we will identify the following distinct regions: (1) Asia, (2) an Asia-Europe trading overlap period, (3) Europe, (4) a Europe-America

Received for publication October 25, 1999. Revision accepted for publication March 22, 2002.

* Arizona State University, and Arizona State University and American Express Co., respectively.

We thank Xixi Yin for excellent research assistance, and Torben Andersen for providing discussion that stimulated this work. Comments on an earlier draft were received from two anonymous referees, the Editor (John Campbell), Seung Chan Ahn, Tim Bollerslev, Maria E. de Boyrie, Takatoshi Ito, Linda Kole, Richard Lyons, Carol Osler, Richard Payne, and participants at the Western Economic Association meeting, the Chemical Bank/Imperial College Conference on Financial Forecasting, and the ASSA meeting. We are responsible for any remaining errors. overlap, and (5) America. These five nonsynchronous market segments will form the basis for our models of volatility transmission. We allow for each region to have unique interrelationships with every other region that would not be possible in a homogenized treatment of the 24-hour day. Since the persistence of volatility may seem surprising to some if markets are free and efficient, it is important to understand the nature of such persistence (if, indeed, any exists) and how it might arise. For this reason, a more precise exploration of the issue that uses high-frequency data and allows for region-specific effects is useful to shed light on the fragility of inferences made from existing studies.

The next section discusses the possible underlying sources of volatility persistence and how a regional framework for analysis may be justified. Section III describes the data and the geographic breakdown of the global foreign exchange market. Section IV introduces our econometric methodology for modeling volatility persistence and presents estimation results. A summary and concluding remarks are contained in section V.

\section{Volatility Persistence and Regional Components}

There is a small but growing literature that addresses the issue of the source of volatility in the FX market. ${ }^{1}$ However, the issue of volatility spillovers from specific market regions is still not well understood. The presence of such spillovers and forecastable volatility in the FX market does not necessarily imply anything about market efficiency or the presence of unexploited profits. However, one might question why prices do not adjust quickly to new information so that the market is characterized by short bursts of volatility rather than the prolonged persistence implied by previous studies.

There are several stories that can be told to try to explain how volatility can spill over from one region of the world into subsequent regions. The persistence of volatility in the FX market could result from seemingly irrational processes such as speculative bubbles or bandwagon effects, but there also exist potential sources that are perfectly compatible with the concept of efficient markets. An obvious candidate is serial correlation in public information arrival. In this case, the market may react quickly and completely to each

\footnotetext{
${ }^{1}$ Andersen and Bollerslev (1998b) provide evidence of the effect of intraday seasonal factors and macroeconomic announcements in explaining $\mathrm{DM} / \$$ volatility. Cai et al. (2001) provide evidence of the same factors, along with big-trader order flow, in explaining $¥ / \$$ volatility. These papers focus on the effects of news releases and constrain the volatility pattern following an announcement to decay at a prespecified rate. Therefore, they do not really address the issues taken up in the current paper.
} 
individual piece of news, but volatility is autocorrelated due to the presence of news clustering over time. Since most news of relevance to financial markets occurs during each region's business hours, we should expect a regular global pattern of intradaily seasonality in the news arrival process that rises and falls with the opening and closing of business hours in each region. As a result, we would expect volatility to follow a similar intradaily pattern. This source of FX market volatility would seem to give rise to the heat-wave effect of regionally specific autocorrelation in volatility, where volatility in Tokyo today is correlated with volatility in Tokyo tomorrow. Since the high-frequency, shortperiodicity FX market studied in this paper is dominated by market-making dealers who typically adjust their positions quickly in response to new information, one might expect that the market reaction to new information would tend to be contained within the region containing the news. This scenario does not explain why volatility would persist across regions.

Another candidate source of volatility persistence that might explain meteor showers, or volatility that is autocorrelated across regions, is that public information received at one point in time is followed with a lag by a stochastic response. Ito et al. (1992) give the example of a U.S. fiscal policy change that creates uncertainty regarding Bank of Japan monetary policy. One can think of many alternative examples. For instance, news arrives in the New York morning regarding the U.S. trade balance, and is followed that afternoon by statements issued by U.S. policy-makers on "needed" policy changes; then further policy-maker responses are forthcoming the next morning in Japan and then Europe. These serially correlated public announcements could cause volatility spillovers from one region to other regions.

Beyond such public-information-based motives for volatility persistence, private information revelation might also be a causal factor. Models of optimizing agents where price gradually incorporates information are provided by Kyle (1985) and Admati and Pfleiderer (1988). In these models, the presence of informed and uninformed agents results in an optimal trading strategy that generates a positive relationship between heterogeneity of expectations, trading volume, and the time required for price to fully reflect information. Easley and O'Hara (1992) construct a model where the speed of adjustment of price to some informational signal is an increasing function of the fraction of informed traders active in the market. Ito, Lyons, and Melvin (1998) provide evidence regarding the importance of private information in the FX market. Position-taking that is based on informational advantages may result in a rippling of trades and generate volatility that is autocorrelated across regions. In this case, we would expect a greater persistence of volatility across regions that overlap in trading hours (for example, Asia and Europe or Europe and America) due to the greater ease of passing positions among traders.
Finally, volatility persistence could exist due to trader heterogeneity of another sort than informational asymmetries. Traders could share information equally but use different models so that information is interpreted differently. In this case, public news arrival could generate trading that persists over time as the market digests the effects of the news. Müller et al. (1997) emphasize traders with different time horizons. For instance, FX dealers are concerned with the extreme short end of the trading spectrum, whereas corporate treasurers or central bankers consider longer horizons. Müller et al. then use this dichotomy to explain their empirical findings that coarsely defined (that is, at lower sampling frequencies) volatility predicts finely defined (that is, at higher sampling frequencies) volatility significantly better than the reverse. Theoretical models of this dichotomy and its effects do not yet exist, but a related model by Osler (1995) is a step in this direction. Though Osler was not concerned with the issue of volatility persistence or prediction, her model suggests a causal sequence where an increase in coarse volatility drives more speculators to the longer trading horizon and then increases short-term volatility as a result. If trader heterogeneity drives volatility persistence, then the degree of such persistence could very easily overlap regions. This is an open empirical question.

Taken as a whole, there are ample theoretical foundations to support the prior belief that volatility in the FX market may be characterized by persistence across geographic regions. Previous empirical studies have documented the presence of such persistence but have not studied the issue using finely sampled data with the regional modeling strategy employed below. The empirical results that follow will modify the inferences yielded by the previous studies and allow a more refined sense of the timing of volatility spillovers based on the regional models employed. Specifically, we will show the economic and statistical significance of the volatility spillovers and the extent to which they tend to be own-region-specific rather than originate from other regions.

\section{Data and Geographic Organization of the Global Market}

Our primary data set consists of tick-by-tick Reuters FXFX spot rate quotes for the Deutsche mark-U.S. dollar (henceforth DM-\$) exchange rate, collected from December 1, 1993 to April 28, $1995 .^{2}$ The work by Dacorogna et al. (1993) and Guillaume et al. (1995) suggests that samples with resolution of at least 10 minutes should be used for reliable statistical analysis. We choose 15-minute intervals as our benchmark periodicity. To infer indicative quotes for each

\footnotetext{
${ }^{2}$ The data were obtained from Olsen and Associates Research Institute for Applied Economics in Zurich.
} 
Figure 1.-Activity on the DM-\$ Market: Mean Daily Quote Frequency Per 15-Minute Interval

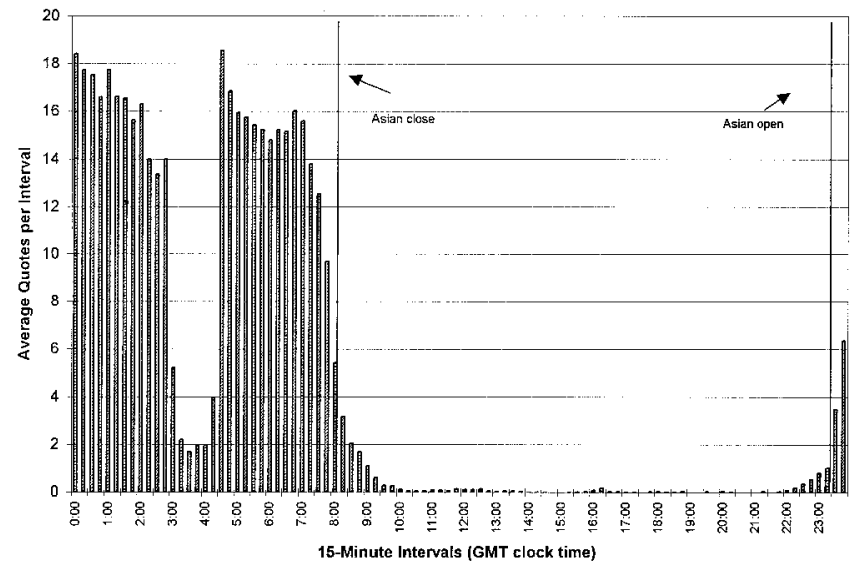

(a)

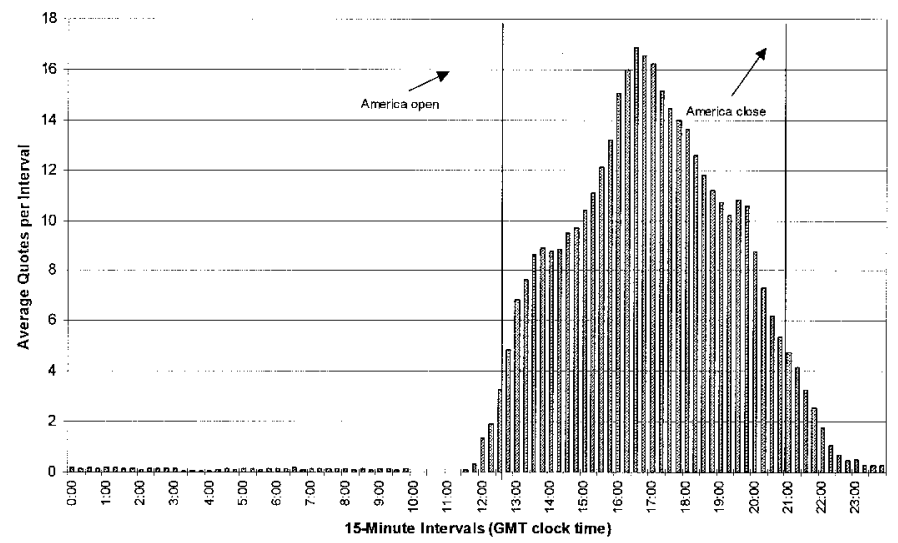

(c)

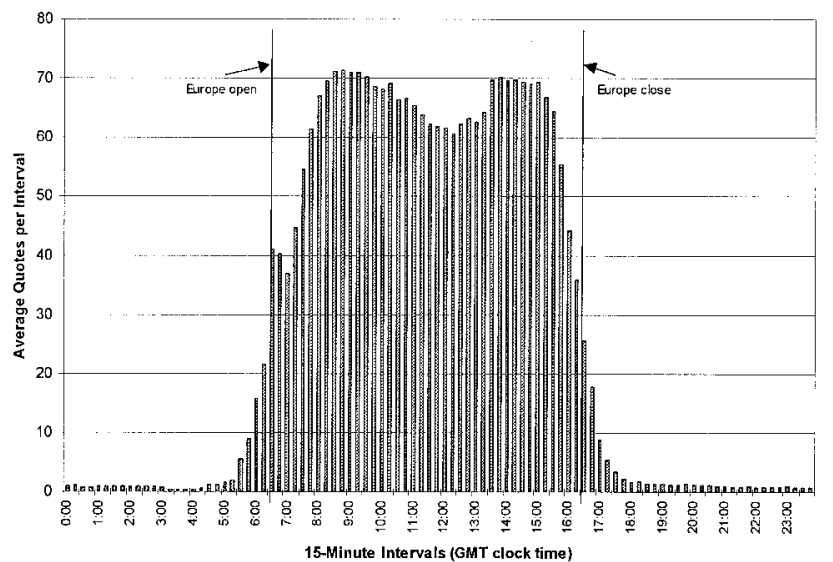

(b)

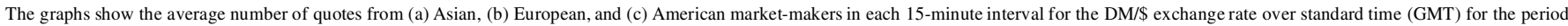
December 1, 1993 to March 28, 1995.

desired 15-minute time point, we follow previous researchers in employing the following interpolation method:

$$
\begin{aligned}
q_{t}^{i}= & 0.5\left[\left(1-\frac{T_{t}-\tau_{t-1}}{\tau_{t+1}-\tau_{t-1}}\right)\left(\ln B_{t-1}^{i}+\ln A_{t-1}^{i}\right)\right. \\
& \left.+\left(1-\frac{\tau_{t+1}-T_{t}}{\tau_{t+1}-\tau_{t-1}}\right)\left(\ln B_{t+1}^{i}+\ln A_{t+1}^{i}\right)\right],
\end{aligned}
$$

where $q_{t}^{i}$ denotes each region i's 15-minute interpolated average of the immediately preceding and following bid-ask midpoint quotes weighted by their relative distance $\tau$, in relation to each 15 -minute clock stamp $T$. The 15 -minute regional quote changes, $\delta q_{t}^{i}$, are then simply measured by the difference between these interpolated indications, multiplied by 10,000 , to convert all units into basis points. To avoid spurious volatility analysis over the much slower weekend trading periods, we follow the lead of most previous research with similar data and eliminate all quotes between Fridays, 23:00 GMT, and Sundays, 22:45 GMT.

Although it is true that the FX market is a 24-hour market, we know that there exists a close intradaily corre- lation between quote frequency and volatility, reflecting the distinct opening and closing times in the major trading centers (see, for instance, Müller et al., 1990). Although Reuters FXFX quotes are indicative prices and hence not identical to actual trading activity, the limited research that has been carried out on transaction data indicates that the volatility of FXFX quote revisions is highly positively correlated with transaction-price volatility (see Goodhart, Ito, and Payne, 1995, for further discussion). Furthermore, the effect of electronic data holes which might affect the timing of tick-by-tick quotes (see Dacorogna et al., 1993, and Zhou, 1996) will be dampened by our coarser time scale, where regional opening and closing times will be based on the average 15-minute quote frequency in each region.

To identify key geographic trading periods, we establish regional groupings based on Reuters quotes. Included are quotes from those countries which hold at least a $1 \%$ market share of total FX turnover, as listed by the Bank for International Settlements (1995, table 3). Figure 1(a) shows the mean number of 15 -minute quotes on the DM-\$ market 
Table 1.-Regional Time Zones Based on Quote Activity in the DM/\$ Market

\begin{tabular}{|c|c|c|c|c|c|}
\hline \multirow[b]{2}{*}{ Sample Period } & \multicolumn{5}{|c|}{ Activity (GMT) } \\
\hline & Asia & Asia-Europe Overlap & Europe & Europe-America Overlap & America \\
\hline 12/1/93-3/26/94 (no DST) & $23: 30-6: 30$ & $6: 30-8: 00$ & $8: 00-12: 30$ & $12: 30-16: 30$ & $16: 30-21: 00$ \\
\hline 3/27/94-4/2/94 (only Eur. DST) & $23: 30-5: 30$ & $5: 30-8: 00$ & $8: 00-12: 30$ & $12: 30-15: 30$ & $15: 30-21: 00$ \\
\hline 4/3/94-9/24/94 (Eur. and Amer. DST) & $23: 30-5: 30$ & $5: 30-8: 00$ & $8: 00-11: 30$ & $11: 30-15: 30$ & $15: 30-20: 00$ \\
\hline 9/25/94-10/29/94 (only Amer. DST) & $23: 30-6: 30$ & $6: 30-8: 00$ & $8: 00-11: 30$ & $11: 30-16: 30$ & $16: 30-20: 00$ \\
\hline 10/30/94-3/25/95 (no DST) & $23: 30-6: 30$ & $6: 30-8: 00$ & $8: 00-12: 30$ & $12: 30-16: 30$ & $16: 30-21: 00$ \\
\hline 3/26/95-4/1/95 (only Eur. DST) & $23: 30-5: 30$ & $5: 30-8: 00$ & $8: 00-12: 30$ & $12: 30-15: 30$ & $15: 30-21: 00$ \\
\hline 4/2/95-4/28/95 (Eur. and Amer. DST) & $23: 30-5: 30$ & $5: 30-8: 00$ & $8: 00-11: 30$ & $11: 30-15: 30$ & $15: 30-20: 00$ \\
\hline
\end{tabular}

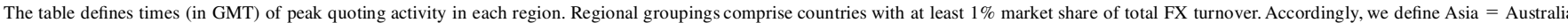

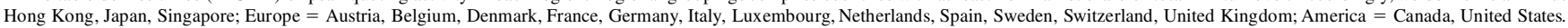

coming from institutions in the following Asian countries: Australia, Hong Kong, Japan, and Singapore. Figure 1(b) shows European quote activity for Austria, Belgium, Denmark, France, Germany, Italy, Luxembourg, the Netherlands, Spain, Switzerland, and the United Kingdom. Finally, figure 1(c) shows the average quote arrival for the American market with Canadian and U.S. quotes of origin. The 15minute indications of figure $1(\mathrm{a})-(\mathrm{c})$ are measured over standard time subsamples (in GMT) across all regions to ensure correspondence of opening and closing hours for all. Note that the vertical scale for Europe is significantly different from that for the other regions, reflecting the greater quote frequency during European business hours.

The activity patterns depicted in the figure provide a clear view of the daily activity passing from one market center to another. To define geographic opening and closing times, we use 24-hour regional mean activity as a threshold signaling the open and close: a mean of 5 quotes per 15 minutes for Asian countries, 28 quotes for Europe, and 4 quotes for America. When 15-minute mean activity is above the respective 24-hour mean, a region is considered open; otherwise, it is considered closed.

Under this criterion, we can identify three distinct time periods where only Asian or European or American traders are active in the market. Moreover, the graphs display two trading overlap periods, in late Asian and early European trading as well as in late European and early American trading. It is well known that the peak period of daily FX market activity occurs when European and American trading overlap (see Guillaume et al., 1995). Hence, price fluctuations during this time period should be treated as an idiosyncratic activity block. The Asia-Europe overlap, on the other hand, has been given little consideration in the literature. Yet, figure 1(a) and (b) demonstrate that the time span of this early overlap period is sufficiently long and market presence sufficiently large for it to be considered a distinct region. The inclusion of these two overlap periods is unique in the analysis of geographic volatility persistence.

Table 1 gives our assessment of reasonable opening and closing hours for each of the five geographic trading blocks, taking into account the daylight saving time shifts in Europe and America. Since the calendar dates for daylight saving time differ in Europe and America, we identify seven separate periods for classifying regional hours. For instance, during the periods of December 1, 1993-March 26, 1994 and October 30, 1994-March 25, 1995, standard time prevailed in both Europe and America. Hence, for these two periods, we identify the following hours: Asia: 23:30-6:30; Asia-Europe overlap: 6:30-8:00; Europe: 8:00-12:30; Europe-America overlap: 12:30-16:30; and America: 16:30 21:00, where all hours are GMT. Alternative regional trading hours based on daylight saving time changes in Europe and America are given in table 1 . We note that the trading hours for each region conform largely to local business hours. The data set used for model estimation is adjusted for these shifts in trading hours so that at each point in time the appropriate lags exist between regions.

\section{Models of Geographic Volatility}

Recent research indicates that estimating daily volatility by summing high-frequency intraday squared returns allows the treatment of daily volatility as observed rather than latent. ${ }^{3}$ As shown in Andersen et al. (ABDL, 2001) the concept of integrated volatility is motivated by the following theory. Consider a continuous-time logarithmic process for the exchange rate quote $q_{t}$ :

$$
d q_{t}=\sigma_{t} d W_{t},
$$

where $t \geq 0, W_{t}$ is a standard Brownian motion, and $\sigma_{t}$ is a strictly stationary process. Then the corresponding discretely sampled returns with $m$ observations per period are given by

$$
r_{(m), t} \equiv q_{t}-q_{t-1 / m}=\int_{0}^{1 / m} \sigma_{t-1 / m+\tau} d W_{t-1 / m+\tau},
$$

where $t=1 / m, 2 / m, \ldots$. The expected returns are equal to 0 , by definition, for all return horizons $m$. Assuming

\footnotetext{
${ }^{3}$ See Andersen and Bollerslev (1998a) and Andersen et al. (2001).
} 
Figure 2.-Regional Volatility Plots
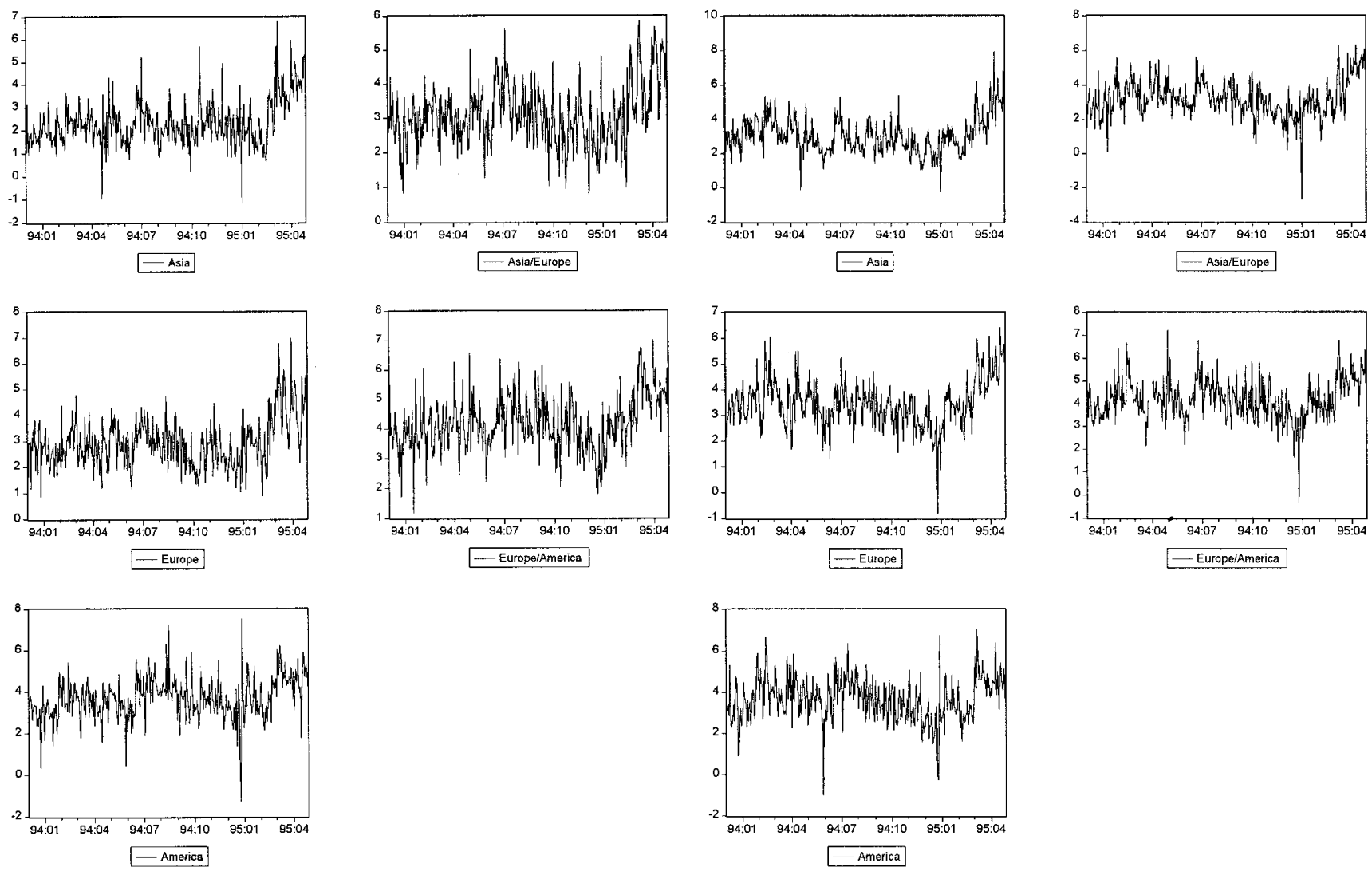

(a)

(b)

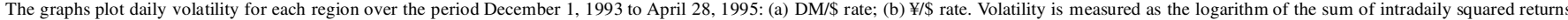
from 15-minute sampling intervals standardized for the number of intervals per region. Time is measured along the horizontal axis and volatility along the vertical axis.

independence of $\sigma_{t}$ and $W_{t}$, the variance of the $h$-period returns, $r_{(1 / h), t+h}$, for $h>0$, is

$$
\sigma_{t, h}^{2} \equiv \int_{0}^{h} \sigma_{t+\tau}^{h} d \tau .
$$

This is the integrated volatility that ABDL show to be a natural definition of asset return volatility in a continuoustime setting. Although this measure is unobservable, ABDL show that by summing high-frequency squared intraday returns, a measure of realized volatility is consistent (in $m$ ) for the integrated volatility as in

$$
\operatorname{plim}_{m \rightarrow \infty} \sum_{j=1, \ldots, m h} r_{(m), t+j / m}^{2}=\sigma_{t, h}^{2} .
$$

We use this result to motivate our use of integrated volatility for daily volatility proxies in each region and treat the resulting volatility measures as an observable, rather than latent, variable. This allows simpler estimation techniques than the usual GARCH models employed in highfrequency volatility analysis. The payoff is that multivariate methods are more easily employed and results are likely to be less model-dependent.
We sum the intradaily squared returns from our 15minute data to create a measure of integrated volatility for each region. This then gives us a daily measure of volatility for each region that serves as the basis for our estimation. Because the regions have different time lengths, we standardize the integrated volatility measures by dividing by the number of 15-minute intervals in each region. As shown in table 1, this will vary with the time of year. Finally, following one of the main lessons of the recent research by Andersen, Bollerslev, Diebold, and coauthors, we use the logarithms of volatility which are closer to normality and reduce the problem of major outliers. Figure 2(a) shows plots of the regional volatility series for the DM/\$ exchange rate, and figure 2 (b) for the $¥ / \$$. Though it is not reported in tables (in order to conserve space), autocorrelation analysis indicates a high degree of autocorrelation in each series, with the $p$-values of the $Q$-statistics equal to 0.00 from the first through $35^{\text {th }}$ lags.

We use these volatility measures to estimate daily volatility regressions. The model to be estimated specifies daily volatility for each region as a function of past volatility of the same region as well as of the volatility of the other regions. In all cases, volatility is measured logarithmically. 
TABle 2.-Wald Tests For OWN-Region and InTERREgion DM/\$ Volatility Persistence

\begin{tabular}{|c|c|c|c|c|c|}
\hline \multirow{2}{*}{$\begin{array}{c}\text { Independent } \\
\text { Regions }\end{array}$} & \multicolumn{5}{|c|}{ Dependent Regions } \\
\hline & AS & $\mathrm{AE}$ & $\mathrm{EU}$ & EA & $\mathrm{AM}$ \\
\hline AS & $\begin{array}{c}29.87 \\
(0.00)\end{array}$ & $\begin{array}{c}19.55 \\
(0.00)\end{array}$ & $\begin{array}{c}3.39 \\
(0.18)\end{array}$ & $\begin{array}{c}9.48 \\
(0.01)\end{array}$ & $\begin{array}{c}0.29 \\
(0.86)\end{array}$ \\
\hline $\mathrm{AE}$ & $\begin{array}{c}0.12 \\
(0.94)\end{array}$ & $\begin{array}{c}26.35 \\
(0.00)\end{array}$ & $\begin{array}{c}26.01 \\
(0.00)\end{array}$ & $\begin{array}{c}0.72 \\
(0.70)\end{array}$ & $\begin{array}{c}2.36 \\
(0.31)\end{array}$ \\
\hline $\mathrm{EU}$ & $\begin{array}{c}27.56 \\
(0.00)\end{array}$ & $\begin{array}{l}16.91 \\
(0.00)\end{array}$ & $\begin{array}{c}10.45 \\
(0.01)\end{array}$ & $\begin{array}{c}2.56 \\
(0.28)\end{array}$ & $\begin{array}{c}14.42 \\
(0.00)\end{array}$ \\
\hline EA & $\begin{array}{c}3.64 \\
(0.16)\end{array}$ & $\begin{array}{c}2.77 \\
(0.25)\end{array}$ & $\begin{array}{c}14.98 \\
(0.00)\end{array}$ & $\begin{array}{c}22.10 \\
(0.00)\end{array}$ & $\begin{array}{c}48.18 \\
(0.00)\end{array}$ \\
\hline $\mathrm{AM}$ & $\begin{array}{c}14.12 \\
(0.00)\end{array}$ & $\begin{array}{c}4.88 \\
(0.09)\end{array}$ & $\begin{array}{c}5.48 \\
(0.06)\end{array}$ & $\begin{array}{c}8.13 \\
(0.02)\end{array}$ & $\begin{array}{c}8.03 \\
(0.02)\end{array}$ \\
\hline $\begin{array}{l}R^{2} \\
p \text {-value, } Q(5) \\
p \text {-value, } Q(35)\end{array}$ & $\begin{array}{l}0.44 \\
0.25 \\
0.16\end{array}$ & $\begin{array}{l}0.46 \\
0.13 \\
0.69\end{array}$ & $\begin{array}{l}0.47 \\
0.60 \\
0.88\end{array}$ & $\begin{array}{l}0.38 \\
0.18 \\
0.03\end{array}$ & $\begin{array}{l}0.50 \\
0.81 \\
0.58\end{array}$ \\
\hline
\end{tabular}

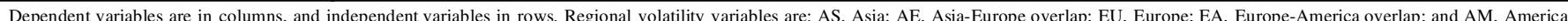

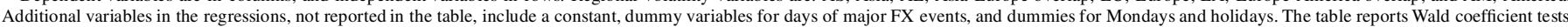

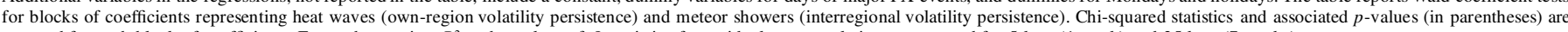
reported for each block of coefficients. For each equation, $R^{2}$ and $p$-values of $Q$-statistics for residual autocorrelation are reported for 5 lags ( 1 week) and 35 lags (7 weeks).

Our system has five equations with volatility in each of our five regions as dependent variables. The timing of the other regional volatility measures included on the right-hand side will differ by region. Since Asia starts the business day, the first lag of other regions will be dated on the prior day for the Asia volatility equation. In the America volatility equation, all the other regions will be dated on the same day for the first lag, because America ends the global business day. The other three regions will have the first lag of those regions that trade earlier on the same date, and regions that trade later will be dated the prior day. In addition to the basic regional volatility measures, we also include dummy variables for days with particularly high volatility. These days generally reflect major movements in exchange rates due to intervention or major news. ${ }^{4}$ The model estimated may be written as

$$
\sigma_{t}^{2}=A_{1} \sigma_{t-1}^{2}+\cdots+A_{p} \sigma_{t-p}^{2}+B x_{t}+\varepsilon_{t},
$$

where $\sigma^{2}$ is a vector containing regional volatility measures, $x$ is a vector of dummy variables for days of major exchange rate events along with a dummy for Mondays and holidays,

\footnotetext{
${ }^{4}$ Dates and regions with dummy variables include: February 14, 1994, when threats of a trade war between the United States and Japan led to the $¥ / \$$ exchange rate exhibiting great volatility during U.S. business hours; April 29, 1994, when the Fed intervened in the $¥$-\$ market during the overlap of European and U.S. business hours; August 16, 1994, when the Fed raised interest rates during U.S. business hours and the DM/\$ exchange rate responded most dramatically; December 28, 1994, when both the mark and yen exhibited great volatility; March 8, 1995, when the Bank of Japan intervened and the dollar hit an all-time low against the yen during Asian and European-Asian overlap business hours, as did the mark during Asian and European business hours; March 19, 1995, when great volatility hit the yen during the overlap of European and Asian hours; March 30, 1995, when the Bundesbank cut interest rates to support the dollar during European business hours; April 10, 1995, when the dollar fell to a record low of 83 yen during Asian business hours; and April 17, 1995, when the dollar hit 81 yen during Asian business hours and the Bank of Japan intervened.
}

$A$ and $B$ are coefficient matrices to be estimated, $t$ is time, and $\varepsilon$ is a vector of innovations. ${ }^{5}$ The lag lengths for the $\mathrm{DM} / \$$ and $¥ / \$$ volatility models are determined by starting with one lag and then evaluating Akaike information criteria and likelihood ratio statistics as additional lags are added. When both statistics reject the next longer lag structure, we stop at the prior lag length. Estimation results for the lag structure that meets these criteria are reported in this paper. This results in two lags for the $\mathrm{DM} / \$$ rate and three lags for the $¥ / \$$. It is important to note that none of the conclusions are changed if we use fewer or more lags than those reported.

The five-equation system is estimated using seemingly unrelated regressions (SUR). Whereas the usual VAR has the same right-side variables in each equation, so that OLS provides efficient estimates, in our case the dating convention used results in different lags on other-region volatility for each equation. In this case, SUR will yield more efficient estimates. Rather than report a long list of individual coefficient estimates, we report tests of significance of blocks of coefficients that represent meteor showers and heat waves for each region.

Table 2 reports results for the DM/\$ model, and table 3 for the $¥ / \$$. The $R$-squares at the bottom of each table indicate that the models contain considerable explanatory power for volatility in each region. In addition, the $p$-values for residual autocorrelation reported for 5 lags (1 week) and 35 lags ( 7 weeks) indicate that there is not much persistence left in the residuals. Of most interest in the tables are the Wald tests for the blocks of lagged volatility variables related to own-region and interregion volatility spillovers. Looking down the diagonals of each table, we see the test statistics and associated $p$-values for own-region volatility

\footnotetext{
${ }^{5}$ Holidays were identified by cross-checking quote frequency with dates of known holidays in major trading centers in each region.
} 
TABle 3.-Wald Tests for OWn-Region and InterRegion ¥/\$ Volatility Persistence

\begin{tabular}{|c|c|c|c|c|c|}
\hline \multirow{2}{*}{$\begin{array}{l}\text { Independent } \\
\text { Regions }\end{array}$} & \multicolumn{5}{|c|}{ Dependent Regions } \\
\hline & AS & $\mathrm{AE}$ & $\mathrm{EU}$ & EA & $\mathrm{AM}$ \\
\hline AS & $\begin{array}{c}42.58 \\
(0.00)\end{array}$ & $\begin{array}{c}28.31 \\
(0.00)\end{array}$ & $\begin{array}{c}12.18 \\
(0.01)\end{array}$ & $\begin{array}{c}8.16 \\
(0.04)\end{array}$ & $\begin{array}{c}3.55 \\
(0.01)\end{array}$ \\
\hline $\mathrm{AE}$ & $\begin{array}{c}14.51 \\
(0.00)\end{array}$ & $\begin{array}{l}17.12 \\
(0.00)\end{array}$ & $\begin{array}{c}13.36 \\
(0.00)\end{array}$ & $\begin{array}{c}3.88 \\
(0.27)\end{array}$ & $\begin{array}{c}8.08 \\
(0.04)\end{array}$ \\
\hline $\mathrm{EU}$ & $\begin{array}{l}14.30 \\
(0.00)\end{array}$ & $\begin{array}{c}3.67 \\
(0.30)\end{array}$ & $\begin{array}{c}9.33 \\
(0.03)\end{array}$ & $\begin{array}{c}23.77 \\
(0.00)\end{array}$ & $\begin{array}{c}4.38 \\
(0.22)\end{array}$ \\
\hline EA & $\begin{array}{l}11.37 \\
(0.01)\end{array}$ & $\begin{array}{c}9.66 \\
(0.02)\end{array}$ & $\begin{array}{c}3.36 \\
(0.34)\end{array}$ & $\begin{array}{c}0.91 \\
(0.82)\end{array}$ & $\begin{array}{l}21.93 \\
(0.00)\end{array}$ \\
\hline $\mathrm{AM}$ & $\begin{array}{c}11.41 \\
(0.01)\end{array}$ & $\begin{array}{c}0.88 \\
(0.83)\end{array}$ & $\begin{array}{c}4.56 \\
(0.21)\end{array}$ & $\begin{array}{l}34.99 \\
(0.00)\end{array}$ & $\begin{array}{c}11.98 \\
(0.01)\end{array}$ \\
\hline $\begin{array}{l}R^{2} \\
p \text {-value, } Q(5) \\
p \text {-value, } Q(35)\end{array}$ & $\begin{array}{l}0.58 \\
0.81 \\
0.68\end{array}$ & $\begin{array}{l}0.49 \\
0.62 \\
0.30\end{array}$ & $\begin{array}{l}0.51 \\
0.98 \\
0.96\end{array}$ & $\begin{array}{l}0.53 \\
0.13 \\
0.06\end{array}$ & $\begin{array}{l}0.48 \\
0.79 \\
0.69\end{array}$ \\
\hline
\end{tabular}

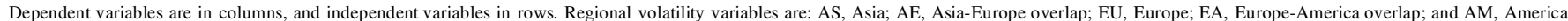

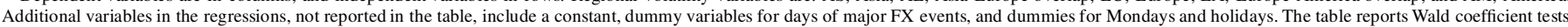

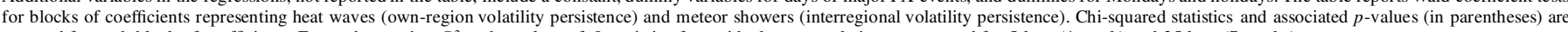
reported for each block of coefficients. For each equation, $R^{2}$ and $p$-values of $Q$-statistics for residual autocorrelation are reported for 5 lags ( 1 week) and 35 lags (7 weeks).

persistence. In table 2, the evidence indicates that ownregion volatility spillovers are all highly statistically significant for the DM/\$ rate. Table 3 suggests the same for the $¥ / \$$, with the exception of the Europe-America (EA) region. Only for this region in $¥$ - $\$$ trading is there a lack of evidence to support the heat-wave hypothesis. Examining the evidence on interregional volatility spillovers for the DM-\$ rate, the evidence indicates that Asian (AS) volatility spills over into Asia-Europe (AE) and Europe-America (EA); AE volatility spills over into Europe (EU); EU volatility spills over into AS, AE, and AM; EA volatility spills over into EU and $\mathrm{AM}$; and $\mathrm{AM}$ volatility spills over into all other regions. The $¥ / \$$ evidence of table 3 indicates that AS volatility spills over into all other regions; AE volatility spills over into all but EA; EU volatility spills over into AS and EA; EA volatility spills over into $\mathrm{AS}, \mathrm{AE}$, and $\mathrm{AM}$; and $\mathrm{AM}$ volatility spills over into AS and EA.

Taken as a whole, there is considerable support for both the heat-wave and meteor-shower hypotheses. The evidence indicates that Asian volatility is quite important as a source of $¥ / \$$ volatility spillovers and that European volatility is quite important as a source of $\mathrm{DM} / \$$ spillovers. Volatility spillovers emanating from America are more relevant for the mark than for the yen.

To have a better idea of the economic significance of the spillovers, we simulate the model for the impact of a one-standard-deviation shock to the innovations of volatility in each region on current and future values of itself and other regions. ${ }^{6}$ Figure 3 contains the $\mathrm{DM} / \$$ impulse re-

\footnotetext{
${ }^{6}$ Because innovations are generally correlated across equations, the order of the endogenous variables in calculating the impulse response functions is important, as the common component is attributed to the variable that comes first in the system. Typically, one must worry about the sensitivity of the ordering to the results, for there is usually no economic reason for having one variable precede another. In our case, this is not so
}

sponse functions for a one-standard-deviation shock to the innovations in each region. Each function is plotted for 10 days (2 weeks). Two-standard-error bands are presented around each estimated function. ${ }^{7}$ Looking down the diagonals of the functions presented, we see the own-region impulse responses, or heat-wave effects. In each case, there is a significant response. The general pattern of response is a fairly steep drop over the first couple of days followed by a few days of gradual decline until the responses are not statistically different from 0 by the end of the 2 -week period. As discussed above, we have standardized volatility in each region so that the integrated volatility measures average volatility per 15 -minute interval. Then the logarithms of this standardized volatility are used for estimation purposes. The transformed volatility measures all have standard deviations close to unity. ${ }^{8}$ This explains why the impulse responses shown along the diagonal in figure 3 start around 1. A one-standard-deviation shock to volatility in any given region will be depicted as starting around 1 and then diminishing over time in the manner shown.

It is instructive now to compare the evidence on the interregional volatility spillovers shown in figure 3. Each row of functions plotted in figure 3 represents one region and shows its response to shocks at home and in the other regions. Each row shows evidence of interregional spillovers that are statistically significantly different from 0 , but

problematic, for the regions proceed in order of their place in the trading day: Asia starts trading each day, and America finishes.

${ }^{7}$ The standard errors of the impulse response functions were calculated via a Monte Carlo exercise where stochastic simulation was conducted with 1,000 repetitions.

${ }^{8}$ Means (standard deviations) of each region's DM/\$ volatility are: AS, 2.32 (1.03); AE, 3.08 (0.95); EU, 2.92 (0.97); EA, 4.19 (0.95); and AM, $3.68(1.02)$. 
Figure 3.-Response of DM/\$ Volatilities to One-Standard-Deviation Shocks
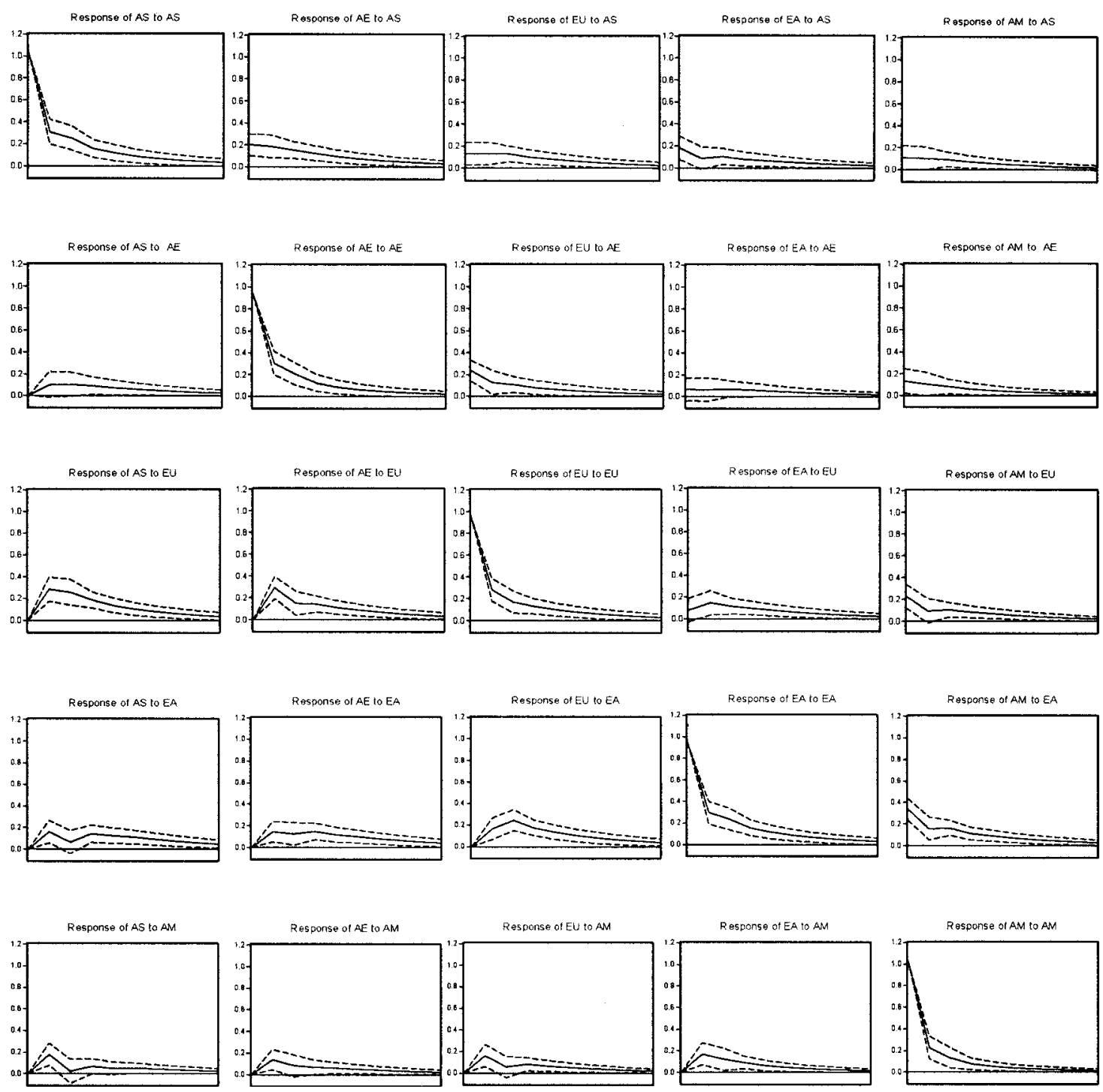

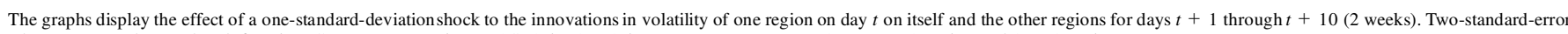
bands are presented around each function. Country mnemonics are AS, Asia; AE, Asia-Europe; EU, Europe; EA, Europe-America; and AM, America.

the economic significance of these spillovers is another matter. Of particular note is how much smaller the effects of interregional volatility spillovers are than those of ownregion spillovers. In every region, the own-region responses are generally 3 to 4 times the magnitude of the interregional responses for the first few lags. So one obvious conclusion is that the economic significance of own-region spillovers is considerably greater than that of the interregional spillovers. In the case of the $\mathrm{DM} / \$$ rate, it appears that heat waves are more important than meteor showers.

Turning now to the $¥ / \$$ responses emanating from a one-standard-deviation shock as reported in figure 4 , we note statistically significant responses existing for ownregion volatility persistence in each region, as illustrated along the diagonal. ${ }^{9}$ Among these heat-wave responses is the notably long persistence of the Asian heat wave out past 2 weeks. Looking along each row of plots in figure 4 , we see the interregional volatility spillovers plotted along with the own-region results. The impulse responses plotted for interregional spillovers indicate statistically significant effects occurring in each region. However, the magnitude is much smaller than the own-region spillovers, and we once again see that the economic significance of the former is dwarfed by that of the latter. As in the case of the DM/ $\$$ exchange

\footnotetext{
${ }^{9}$ Means (standard deviations) of each region’s $¥ / \$$ volatility are: AS, 3.07 (1.08); AE, 3.22 (1.14); EU, 3.46 (0.95); EA, 4.21 (0.92); and AM, 3.64 (1.08).
} 
Figure 4.-Response of $¥ / \$$ Volatilities to One-Standard Deviation Shocks
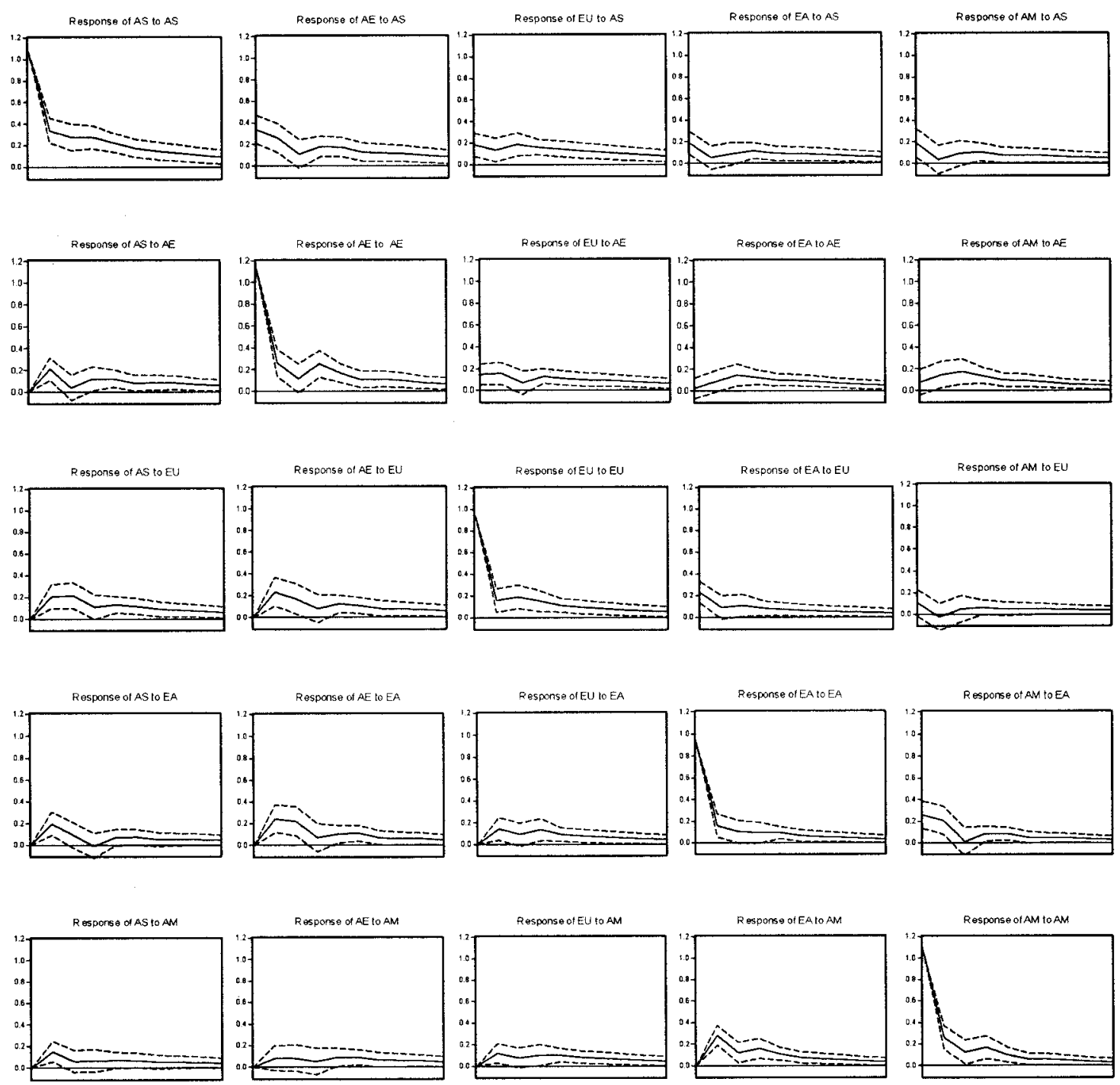

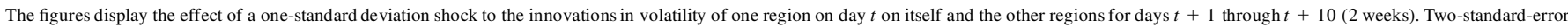
bands are presented around each function. Country mnemonics are AS, Asia; AE, Asia-Europe; EU, Europe; EA, Europe-America; and AM, America.

rate, it appears that meteor showers are less important than heat waves for the $¥ / \$$ exchange rate.

\section{Summary and Conclusion}

This paper has explored the evidence regarding volatility persistence in $\mathrm{DM} / \$$ and $¥ / \$$ quotes for separate regional models. An examination of the quoting patterns of institutions located in different regions reveals that five regions emerge as candidate trading centers for volatility models. These five regions are Asia, the Asia-Europe overlap, Europe, the Europe-America overlap, and America. Daily models of integrated volatility are then built and estimated for each region where the volatility of exchange rate returns is a function of the volatility in the previous day for each region (the heat-wave effect, or own-region volatility persistence) and the earlier volatility of other regions (the meteor-shower effect, or interregional volatility persistence).

Results presented indicate that estimates differ across regions, lending support to the notion that regions have unique characteristics such as institutions or relationships with other regions that are only revealed through individual regional modeling. Findings include the following: First, regions differ in their inherent volatility. This is a result that has been shown in earlier papers that model the highfrequency pattern of quotes and volatility in the FX market [see Dacorogna et al. (1993) for an early example, and Andersen and Bollerslev (1997) or Melvin and Yin (2000) for more recent examples]. More important in the present paper is the finding that own-region volatility spillovers are more significant economically (larger in magnitude) than interregional spillovers. In terms coined by Engle et al. 
(1990), heat waves are more important than meteor showers.

We want to highlight the finding that, while the Wald tests and impulse response functions associated with interregional spillovers indicate some evidence of responses significantly different from 0 for several days, the impulse responses clearly illustrate that the economic significance appears to be slight compared to that of the own-region spillovers. The latter appear to occur as a sharp burst of own-region volatility following a shock that dissipates over several days. The one exceptional region in this regard was the Asia region for yen volatility, which had own-region spillovers that persisted beyond 2 weeks. Yet even in this case, it is noteworthy that the large magnitude of the volatility response occurs in the first 2 days following the shock.

Some may argue that volatility that persists for prolonged times is inconsistent with an efficient market where prices are free to adjust instantly to new information. However, there are arguments to be made for FX market shocks taking some time to ripple through the market. ${ }^{10}$ Our results suggest that the ripples are most significant in a region-specific or home-market context and tend not to spill over to other countries in economically significant magnitudes. This view of the normal functioning of the FX market supports the sources of FX volatility being primarily local: whatever causes a volatility spike in one region today is related to higher-than-normal volatility in the same region tomorrow. Though there may be some ripples of volatility into other regions, the magnitude is small relative to the home-market effects.

\section{REFERENCES}

Admati, A., and P. Pfleiderer, "A Theory of Intraday Patterns: Volume and Price Variability," The Review of Financial Studies 1 (1988), $30-40$.

Andersen, Torben, and Tim Bollerslev, "Intraday Periodicity and Volatility Persistence in Financial Markets," Journal of Empirical Finance 4 (1997), 115-158.

_ - "Answering the Skeptics: Yes, Standard Volatility Models Do Provide Accurate Forecasts," International Economic Review 39 (1998a), 885-905.

_ , "Deutsche Mark-Dollar Volatility: Intraday Activity Patterns, Macroeconomic Announcements, and Longer-Run Dependencies," Journal of Finance 53 (1998b), 219-265.

Andersen, Torben, Tim Bollerslev, Francis Diebold, and Paul Labys, "The Distribution of Realized Exchange Rate Volatility," Journal of the American Statistical Association 96 (2001), 42-55.

\footnotetext{
${ }^{10}$ See section II for discussion of this issue.
}

Baillie, Richard, and Tim Bollerslev, "Intra-day and Inter-market Volatility in Foreign Exchange Rates," Review of Economic Studies 58 (1990), 565-585.

Bank for International Settlements, Central Bank Survey of Foreign Exchange Market Activity in April 1995: Preliminary Global Findings (Basel, 1995).

Cai, Jun, Yan-Leung Cheung, Raymond S.K. Lee, and Michael Melvin, "Once-in-a-Generation Yen Volatility in 1998: Fundamentals, Intervention, and Order Flow," Journal of International Money and Finance 20 (2001), 327-348.

Dacorogna, Michel, Ulrich Müller, Robert Nagler, Richard Olsen, and Olivier Pictet, "A Geographical Model for the Daily and Weekly Seasonal Volatility in the Foreign Exchange Market," Journal of International Money and Finance 12 (1993), 413-438.

Easley, David, and Maureen O'Hara, "Time and the Process of Security Price Adjustment," The Journal of Finance 47 (1992), 577-605.

Engle, Robert F., Takatoshi Ito, and Wen-Ling Lin, "Meteor Showers or Heat Waves? Heteroscedastic Intra-daily Volatility in the Foreign Exchange Market," Econometrica 59 (1990), 525-542.

Goodhart, Charles, Takatoshi Ito, and Richard Payne, "One Day in June, 1993: A Study of the Working of Reuters 2000-2 Electronic Foreign Exchange Trading System" (pp. 107-179), in J. Frankel, G. Galli, and A. Giovannini (Eds.), The Microstructure of Foreign Exchange Markets (Chicago: The University of Chicago Press, 1996).

Guillaume, Dominique M., Michel M. Dacorogna, Rakhal R. Dave, Ulrich A. Müller, Richard B. Olsen, and Olivier V. Pictet, "From the Bird's Eye to the Microscope: A Survey of New Stylized Facts of the Intradaily Foreign Exchange Markets," Finance and Stochastics 1 (1995), 95-129.

Hogan Jr., Kedreth C. and Michael Melvin, "Sources of Meteor Showers and Heat Waves in the Foreign Exchange Market," Journal of International Economics 37 (1994), 239-247.

Ito, Takatoshi, Robert F. Engle, and Wen-Ling Lin, "Where Does the Meteor Shower Come From? The Role of Stochastic Policy Coordination," Journal of International Economics 32 (1992), 221-240.

Ito, Takatoshi, Richard K. Lyons, and Michael T. Melvin, "Is There Private Information in the FX Market? The Tokyo Experiment," Journal of Finance 53 (1998), 1111-1130.

Kyle, A. S., "Continuous Auctions and Insider Trading," Econometrica 53 (1985), 1315-1335.

Melvin, Michael, and Xixi Yin, "Public Information Arrival, Exchange Rate Volatility, and Quote Frequency," Economic Journal 110 (2000), 644-661.

Müller, Ulrich, Michel Dacorogna, Robert Olsen, Olivier Pictet, M. Schwarz, and C. Morgenegg, "Statistically Study of Foreign Exchange Rates, Empirical Evidence of a Price Change Scaling Law and Intradaily Analysis," Journal of Banking and Finance 14 (1990), 1189-1208.

Müller, Ulrich A., Michel M. Dacorogna, Rakhal D. Dave, Richard B. Olsen, Olivier V. Pictet, and Jakob E. von Weizsäcker, "Volatilities of Different Time Resolutions-Analyzing the Dynamics of Market Components," Journal of Empirical Finance 4 (1997), 213 240.

Osler, Carol L., "Exchange Rate Dynamics and Speculator Horizons," Journal of International Money and Finance 14 (1995), 695-720.

Zhou, Bin, "High Frequency Data and Volatility in Foreign Exchange Rates," Journal of Business and Economic Statistics 14 (1996), $45-52$. 